about parents' involvement clinical visits and autonomy of parents in decision-making processes.

\section{P0-0890 THE SELF-RESPECT AND SCHOOL SUCCESS OF THE HEALTHY SIBLINGS OF THE MENTALLY DISABLED CHILDREN}

B Koc, S Polat. Nursing, Bozok University School of Healthy, Yozgat, Turkey

10.1136/archdischild-2014-307384.1512

Background This descriptive study was conducted in order to determine the self-respect and school success of the healthy siblings of the trainable mentally disabled children.

Methods The data of the study was collected by informative data form and Coopersmith Self- Esteem Scale between. The school grades of the healthy siblings at the end of the year were obtained from e-school system. The healthy siblings of 91 mentally disabled children who are getting private training and who have siblings were icluded in the study.

Results The healthy siblings of the mentally disabled children icluded in the study, $42.8 \%$ were between the ages of $12-14$ and $57.1 \%$ were female, $42.8 \%$ were attending second-level primary school classes. The self-respect point average of the healthy siblings of the mentally disabled children was $59.2 \pm 14.9$; and $69.2 \%$ of them had medium level, $27.5 \%$ of them high level of self-respect. The self-respect of the healthy siblings was affected by the gender of the mentally disabled sibling and the employment status of the father. The school success level of $60.4 \%$ of the healthy siblings at the end of the year was found to be 'good'.

Conclusion Supporting the self-respect and school success of the healthy siblings of the mentally disabled children in a way that they would not be affected by their siblings' disability, the families' sparing enough time for the daily needs of the healthy children and their performences at school, improving the cooperation between parents.

\section{PO-0891 YOUR NEW FRIEND, CALLED CHANGE: EFFECTIVE IMPLEMENTATIONS ON YOUR WARD BY TRAINING THE KEY PLAYERS}

${ }^{1} \mathrm{~K}$ Unk, ${ }^{2} \mathrm{H}$ Vermeulen, ${ }^{3} \mathrm{TA}$ Slagter, ${ }^{4} \mathrm{HH}$ Greuter, ${ }^{1} \mathrm{JM}$ Maaskant. 'Women's and Children's Clinic, Academic Medical Center, Amsterdam, Netherlands; ${ }^{2}$ Department of Surgery Amsterdam School of Health Professions, Academic Medical Center, Amsterdam, Netherlands; ${ }^{3}$ Quality and Safety Committee, Academic Medical Center, Amsterdam, Netherlands; ${ }^{4}$ Department of Quality Assurance and Process Innovation, Academic Medical Center, Amsterdam, Netherlands

10.1136/archdischild-2014-307384.1513

Background and aims Continuous quality improvement (QI) in healthcare is necessary. However many publications prove that often the implementation of innovations fails in daily hospital practice. We found a lack of knowledge and skills within the executing staff of our children's clinic in this field. The aim was to develop and realise an efficient and effective training to empower the responsible staff nurses in order to improve the success rate of QI implementation projects on the wards.

Methods After a critical analysis we developed basic principles for this training:

- 'learning on the job'; students are using their own project during the course
- focus on key elements of implementation and necessary competencies

- immediately applicable in daily practice

- the use of already in-hospital available knowledge

- thorough quantitative and qualitative evaluations (oral and written).

Results In 2013 we developed, realised and evaluated this implementation training;

- developed by 6 professionals from 4 different fields

- training in 4 daily periods (afternoons) in a 3-4 weeks interval

- based on 4 implementation key-topics and 7 implementation competencies

- 14 students; simultaneously invested in their own QI projects

- student-scores (scale: 1-5) mean total training: 3.5

- high scores: applicability (4.4), personal learning efficiency (3.6), trainers (3.9).

Discussion/conclusion We successfully designed and realised a training to improve the implementation knowledge and skills of the nursing staff. At present we are improving the training (based on the evaluation figures), in the next phase we will implement this training hospital-wide.

\section{PO-0892 ASK A STUDENT; THE LOGICAL SOLUTION. A, PROVEN EFFECTIVE, PATHWAY TO CONTINUOUSLY UPDATE YOUR PROTOCOLS AND THE PERMANENT AVAILABILITY OF NURSE STUDENT GRADUATION SUBJECTS}

K Unk, MG Jansen, CJ van der Perk, JM Maaskant. Women's and Children's Clinic, Academic Medical Center, Amsterdam, Netherlands

\subsection{6/archdischild-2014-307384.1514}

Background and aims It is important to continuously optimise the nursing protocols based on the latest available evidence. Besides this paediatric nurse students are often searching for suitable graduation subjects. The aim was to develop and implement an efficient and effective model combining and meeting these demands, regarding the nursing staff of our children's hospital.

Methods We designed a systematic procedure, combining different key elements:

- Finding evidence based answers to clinical problems.

- Continuous input to optimise the nursing protocols.

- Permanent available student graduation subjects (thesis).

- Motivating both nursing staff and nurse students.

Results After development (2011), we implemented, evaluated and improved this method in 2012.

- The procedure contains 5 steps (from graduation subject to presenting results).

- Clear agreements about results and deadlines (form for each project + written approval).

- Clear description of steps and responsibilities of the 5 different professionals involved.

-2012-2013: 49 recommendations/graduation subjects, resulting in 27 adjusted/updated protocols.

- Start 2014: our databank contains 100 graduation subjects to improve the protocols.

- Efficient use of the already local available EBP knowledge and skills.

Discussion/conclusion We successfully designed, implemented, evaluated and improved an effective and efficient intervention in a children's hospital. We found a solution for: (a) the permanent 